\title{
Artelogie
}

artelogie Recherche sur les arts, le patrimoine et la littérature de l'Amérique latine

14 | 2019

Sensibilités : Arts, littératures et patrimoine en

Amérique latine

\section{Joel Silveira: um repórter em diretrizes}

Joëlle Rouchou

\section{OpenEdition}

Journals

Edição electrónica

URL: http://journals.openedition.org/artelogie/3926

DOI: 10.4000/artelogie.3926

ISSN: 2115-6395

\section{Editora}

Association ESCAL

Refêrencia eletrónica

Joëlle Rouchou, « Joel Silveira: um repórter em diretrizes », Artelogie [Online], 14 | 2019, posto online no dia 07 janeiro 2019, consultado o 17 setembro 2019. URL : http://journals.openedition.org/ artelogie/3926 ; DOI : 10.4000/artelogie.3926

Este documento foi criado de forma automática no dia 17 Setembro 2019.

Association ESCAL 


\title{
Joel Silveira: um repórter em diretrizes
}

\author{
Joëlle Rouchou
}

A pesquisa para a produção deste artigo contou com a colaboração fundamental do bolsista PIBIC/

$\mathrm{CNPq}$ Yuri Resende, que contribuiu com o levantamento de informações e com as discussões a respeito das matérias publicadas por Joel Silveira em 'Diretrizes'.

\section{Introdução}

1 Dois anos antes da criação da revista Diretrizes (1938-1944), o jornalista Joel Silveira já se interessava por literatura e pelos escritores, morando na sua Aracaju natal. Em sua autobiografia Na fogueira - memórias, Joel conta como foi com outros 4 alunos do colégio Ateneu Pedro II até a casa de Jorge Amado para conhecer o escritor. Na cara e na coragem, pediram licença para entrar no casarão do pai de Amado, João, na cidade de Estância. Queriam conhecer o ídolo. o baiano os recebeu em sua rede. Estava se escondendo de uma caça aos comunistas - logo após o fracasso da chamada Revolta Comunista em 1935 resolvendo passar uns dias recolhido. “- Somos alunos do Ateneu Pedro II, de Aracaju... Sem deixar a rede, e após apertar a mão de todos nós, Jorge falou: - vocês me desculpem eu não me levantar. É que sair e entrar nesta rede dá uma trabalheira dos diabos (...)" (SILVEIRA, 1998: p. 18)

2 Os alunos ficaram fascinados pelo escritor, um herói desses tempos pré-guerra. As democracias estavam em perigo na Europa, Hitler e Mussolini protagonizavam o panorama político com ideias fascistas, e eles acompanhavam o noticiário pelas ondas da rádio $\mathrm{BBC}$, de Londres. As notícias chegavam também pela assinatura do pai de Joel de $\mathrm{A}$ noite, o Globo o Jornal do Comércio, que vinham de navio, sempre atrasados em relação às datas das capas.

3 Lia revistas cariocas, entre elas 0 malho e Para-Todos, e o jornal A Tarde de Salvador trazia informações mais recentes. Militância política estudantil, vontade de estudar mais, deixaram a capital de Sergipe pequena demais para Joel. Em 1937 decide ir par ao Rio de Janeiro fazer um curso de Direito, e assim desembarcou na Praça Mauá, a bordo do navio 
Itanagé. No Rio, se decepciona com a faculdade de Direito e decide ganhar a vida escrevendo textos. Seu interesse pela escrita, o move no sentido de construir uma rede de contatos ligados essencialmente à literatura e vai seguindo sua intuição e a necessidade financeira para conseguir publicar crônicas. Assim, graças a seu talento e perseverança, publica na revista Vamos Ler seu primeiro livro, Desespero, que havia sido vencedor de um concurso literário ainda na escola. Fica amigo de Raimundo Magalhães Jr que percebe o talento e lhe oferece espaço para publicar crônicas, entrevistas e assim Silveira vai conseguindo sobreviver no Rio de Janeiro. A partir dos novos amigos e buscando sempre manter uma turma de colegas mais afinados com suas posições políticas anti-getulistas, Silveira vai trabalhar na redação de Dom Casmurro, dirigida à época pelo poeta e jornalista Alvaro Moreyra. Permanece na redação por três anos e logo depois vai para a redação de Diretrizes, sob comando do jornalista Samuel Wainer, numa redação combativa, sofrendo censura do DIP (Departamento de Informação e Propaganda) mas com seus pares fortalecidos pela luta pela liberdade de imprensa. Esse sentimento de escrever como arma por um mundo mais justo, vai perpassar a carreira de Joel. Mas nesse momento ainda com com 20 e poucos anos, o sentimento e a garra ficam mais evidentes e intensos. Ele entra como repórter e em pouco tempo chega ao posto de secretário de redação. "Na verdade, nós jornalistas, naqueles primeiros tempos do Estado Novo (ou melhor, durante todo ele), sabíamos mais do que passava no país e no governo do que o povão brasileiro. Com seus telefonemas, o DIP de Lourival Fontes acabava nos informando indiretamente de tudo que a censura não permitia que fosse divulgado pelos jornais; ou então nos dava a pista para aquilo que só nos era informado pela metade. O clima (...) em todas as redações do Brasil tornava-se pesado, sufocante, já não pilheriávamos tanto" (...).(SILVEIRA, 1998)

4 O fato de estar na revista não o impedia de colaborar com outras publicações como Vamos Ler, e Carioca (que faziam parte do grupo A Noite). Em Diretrizes, contabilizamos mais de quarenta textos entre reportagens e crônicas, que costumavam ser destacadas nas edições da revista. Sai a revista quando ela termina em 1944, vítima de perseguições políticas. Segue na profissão, no mesmo ano trabalhando nos Diários Associados de Assis Chateaubriand. Lá teve a oportunidade de se tornar correspondente de guerra, e em 23 de novembro de 1944 embarca com 6 mil soldados rumo à Itália. Em seu primeiro relato, Joel sente o peso da entrada na guerra: "Escrevo esta minha primeira reportagem após 22 horas a bordo do transporte que nos desembarcará dentro de 16 dias em Nápoles. A mim e a cerca de seis mil soldados brasileiros que comigo seguem para a guerra. É um mundo estranho e misterioso que possivelmente levará muito tempo para ser revelado. Ando pelos porões do imenso navio, perco-me em seus corredores que parecem não ter fim, e cada porta de ferro se abre para uma nova surpresa. (...) Estamos em guerra, somos uma multidão que segue para a guerra, e muita coisa não se deve fazer: não se deve, por exemplo, atirar qualquer coisa ao mar. Sou apenas um recruta, bisonho e desprevenido como todo recruta, um pobre e indefeso civil em poucas semanas transformado num soldado da ativa, e me emaranho e me confundo num mundo que nunca foi meu. (...) Bem, meu nome é Joel Silveira, jornalista de 26 anos, e estou indo para a guerra. Voltarei? Lembro-me das palavras de Assis Chateubriand, meu padrão, quando dele me fui despedir, já devidamente fardado: 'Seu Silveira, me faça um favor de ordem pessoal. Vá para a guerra mas não morra. Repórter não é para morrer, é para mandar notícias.'. Prometi obedecer cegamente a suas ordens, e tenho de cumprir a promessa". (SILVEIRA, 1983)

5 Joel Silveira cobre a guerra ao longo de nove meses, incluindo a tomada brasileira da cidade de Monte Castelo Cobriu também, em Milão, a execução do ditador Benito Mussolini, em Milão. Em 1947 foi um dos fundadores do Partido Socialista Brasileiro, faz 
parte do conselho editorial da Revista Nacional, passou pela Revista da Semana e em 1952, com o amigo e escritor Rubem Braga, funda o jornal 0 comício. Quatro meses antes do suicídio de Getúlio Vargas em agosto de 1954, Joel consegue uma entrevista com o presidente. Nos dez anos seguintes, o jornalista trabalha no Serviço de Documentação do Ministério do Trabalho e colabora no jornal Correio da Manhã. Durante ditadura, Joel faz reportagens para a revista Manchete e decide deixar as redações para se dedicar a projetos de escrita de suas memórias, o que faz com sucesso. Entre os títulos estão 0 inverno da guerra (Objetiva, 2005) e II Guerra: momentos críticos (Mauad, 1995).

\section{0 trabalho em Diretrizes}

6 Num primeiro momento, a revista foi mensal, e dois anos depois, passou a ser uma publicação semanal. Durante seus mais de 200 números, o hebdomadário conseguiu independência dos demais jornais e revistas do país, buscando liberdade de expressão e uma linguagem reflexiva em seus textos pertinentes. Foram vários embates com o severo Departamento de Imprensa e Propaganda, o DIP, criado por decreto presidencial em 1939 e dirigido por Lourival Fontes. Foram dezenas de artigos censurados, embates permanentes com o DIP, diversas tentativas de burlar a censura algumas com sucesso, outras não. O governo de Vargas mantinha relações simpatizantes ao Eixo, logo que eclodiu a II Guerra Mundial e o jornalista Samuel Wainer, defendendo ideias liberais e acreditando em alguma imparcialidade da imprensa, lutou, junto com seus colegas de redação, pela diversidade das informações.

7 A luta durou cerca de dois anos, pois assim que o Brasil em 1942 entra ao lado dos Aliados na guerra, a revista inaugura um novo momento com maior liberdade, sem pressão do DIP. Durante a Segunda Guerra, a revista pode expandir suas ideias liberais e democráticas, pois o Brasil esteve ao lado dos Aliados. Apoiou a entrada do país na Guerra em 1942, publicava artigos contra os países do Eixo e levantou bandeiras importantes como o apoio à siderurgia nacional, a campanha do "petróleo é nosso" e ataque incondicional ao nazi-fascismo. Para WERNECK SODRÉ, Wainer conseguiu com elegância e persistência, esgueirar-se pela rígida estrutura estadonovista: "(...) com esforços curiosos, muita malícia e alguma ousadia, passando assunto entre as estreitas malhas do vastíssimo rol dos assuntos proibidos, essa revista teve, realmente, papel de relevo na época, que foi ainda maior à medida em que, desde 1942 (...), os Estados Unidos juntaram-se aos Aliados. A participação da União Soviética na guerra, forçando a suspensão da propaganda anticomunista no ocidente, permitiu o combate ao nazi-fascismo e o Estado Novo começou a ser esvaziado de seu conteúdo originário e a debilitar-se" (WERNECK SODRÉ, 1999: p. 386)

8 Silveira foi uma estrela enquanto repórter e dirigente da revista. Aquela redação, com amigos unidos pelo ideal anti estadonovista, contra a censura e vivendo uma sociabilidade ao mesmo tempo boêmia e militante pelo fim da censura e defendendo ideias libertários, formou uma geração importante de intelectuais e jornalistas em tempos de sensíveis pré, durante e pós II guerra, vivendo no Rio de Janeiro, capital federal. Construíam textos e laços de amizade entre literatos e jornalistas, num tecido costurados pelo ideal. SANDRA PESAVENTO chama atenção para essa rede de sociabilidade que se forma nas cidades, apontando agentes, relações sociais, grupos: "A cidade é concentração populacional, tem um pulsar de vida e cumpre plenamente o sentido da noção do habitar, e essas características a tornam indissociavelmente ligada ao sentido do humano: cidade, lugar do homem; cidade, obra coletiva que 
é impensável no individual; cidade, moradia de muitos, a compor um tecido sempre renovado de relações sociais". (PESAVENTO, 2007)

Joel conquistou a cidade, fixou-se nela, deixando para trás a Aracaju natal que não tinha espaço para seu talento. Seus textos foram seminais para um estilo jornalístico que misturava técnicas e estilo literários, o que e convencionou chamar de jornalismo literário, uma apropriação do estilo de New Journalism americano, escola que teve Gay Talese, Truman Capote, Norman Mailer e Tom Wolfe. Foi uma era pré-lead, a técnica jornalística que vai se formar nos anos 50 com um estilo mais conciso, resumindo todas as informações no primeiro parágrafo da matéria (o lead) que contém as perguntas básicas para transmissão das informações: O quê? Por quê? Como? Aonde? Quem? Quando?

Em Diretrizes emplacou diversas capas, mais de doze entrevistas, e muitas delas foram o destaque de capa de suas respectivas edições. Destacamos aqui algumas matérias, concentradas entre os anos de 1942 e 1943, nas quais o jornalista optou por conversar com intelectuais renomados que emitiram opiniões a respeito da Segunda Guerra Mundial e da ameaça do fascismo no território brasileiro. Foram eles: João Neves da Fontoura, J. Carlos, Góis Monteiro, Gabriel Gonzalez Videla, Ernesto Feder, Monteiro Lobato e Mauricio de Lacerda. É uma produção importante dentro da profissão de repórter, e Joel se apresenta como um dos melhores de sua geração. Vale chamar a atenção que os tempos eram sombrios, o mundo viva a Segunda Guerra mundial, iniciada em 1939, muitas dúvidas e preocupações nas reuniões de pautas e nas ruas, sobre a posição política e o rumo que o Brasil seguiria naqueles anos. Seguem alguns exemplos com resumo do conteúdo para que se possa perceber a qualidade das pautas, a escolha dos assuntos que misturavam a vida em sociedade, política, críticas ao integralismo.

11 Por não caber a análise de todos os artigos, optamos por disponibilizar uma pequena seleção do que consideramos o mais interessante e pertinente na escrita de Silveira (ver Tabela 1, em anexo ao fim do artigo).

12 As reportagens eram muito bem apuradas, com personagens bem desenhados e escolhidos além de uma sensibilidade para descrevê-los. Em Escravos do contato ( DIRETRIZES, 1941: ED 49, p. 12-13) Joel descreve a história de Joca, o negrinho que venceu Procópio, uma história que se desenrola num barracão em Cachambi. Um diretor de cinema português, Chianca de Garcia, desembarca no Rio para filmar o romance de José Lins do Rego, Pureza. "Retratava o ambiente acanhadíssimo de uma estação ferroviária da Great Western, perdida no sertão nordestino. Duas moças, coitadas, viviam ai, com uma porção deilusões na cabeça e doidinhas para ganhar a cidade. Queriam amar, e não encontravam ninguém. Então tomavam banho no riacho, passeavam pela mata e viam todos os dias, os trens passarem. Havia um pai, havia uma mãe. um molequinho, uma negra gorda, dois rapazes, sendo- que um era de lá mesmo, e o outro um franzino que viera doente aspirar o ar do campo. Muito bem. $O$ leitor vê logo que o livro pode ser muito bom, mas o ambiente é por demais curto para um filme". (DIRETRIZES, 1941: ED 49, p. 12)

13 O que Silveira trouxe para seu leitor não foi a história completa do romance, mas a vida de Joca, Jayme Pedro da Silva, o jovem que protagonizou o filme por quem o jornalista se encantou. Joca, 14 anos, era filho de dona Leopoldina, órfão de pai aos 3, e a possibilidade se tornar ator, animou a vida de Dona Leopoldina e seus filhos, assim entraria algum dinheiro para sustentar a família moradora do Meier. Silveira descreve a esperança de toda a família quando Chianca o contrata para fazer o filme e o inscreve numa escola. “(...) Ora, é lógico que Jóca pensava em diversas coisas que poderiam acontecer. Por exemplo: em arranjar um emprego melhorzinho, um bom ponto de jornal, uma barbearia mais pródiga, etc. Isso 
não quer dizer que Jóca não sonhasse. Sonhava e sonha. De vez em quando, nas noites úmidas do barracão de Cachambi, Jóca sonhava que era rico. Bem como os sonhos de d. Leopoldina com o seu filho Hélio. Mas Jóca nunca sonhou em ser artista de cinema. Isso não! De maneiras que quando Chianca chegou e perguntou se Jóca queria trabalhar num filme, o negrinho ficou calado, procurando onde estava o espirito da brincadeira. Mas depois viu que não era brincadeira nem nada, o português estava falando serio. O português falava assim:

- Nós estamos fazendo um filme que vai se chamar "Pureza". Um dos interpretes do filme é um negrinho - está no argumento. Falta-nos este negrinho. Apelamos para você. Pagamos $40 \$ 000$ por filmagem que você faça. Feito?" (DIRETRIZES, 1941: ED 49, p. 13)

Começava uma nova fase na vida de Joca, indo aos estúdios da Cinédia, ficou amigo de José Lins do Rego e Doriaval Caymmi. Mas a crítica não aprovou o filme e depois das filmagens Joca ficou sem fazer nada e a denúncia de Joel era exatamente em contar a história do menino que sentira o gosto pelas telas e pela sedutora vida nos palcos e nas telas. Joca lembra a história do personagem Pixote, de Hector Babenco (1981) quando o ator Fernanda Ramos Sá, um menino excluído social foi selecionado para interpretar o menino de rua. Acabou sendo executado aos 19 anos, em 1981. Joca não quis voltar para a vida em Cachambi e resolveu seguir carreira e foi até o Cassino da Urca: “- Eu sou Jóca, aquele negrinho dc "Pureza". Sei cantar, interpretar qualquer coisa, vim pedir um emprego ao senhor. Quero trabalhar no cassino. (...) / Sr. Rolas remeteu Jóca para Luiz Peixoto, que, por sua vez, passou-o ás mãos de Chiquinho Sales. Chiquinho começou a ensaiar Jóca nos sambas de breque. Rolas viu logo que o negrinho dava certo. Fez um contrato e mandou Jóca assinar: - Enquanto você estiver ensaiando ganhará trezentos mil réis mensais. Logo que comece a trabalhar, receberá seiscentos mil réis. E de seis em seis meses será aumentado em 100\$000. / (...) Mas, de qualquer maneira Jóca está preso, por contrato, durante três anos. Não poderá fazer nada, não poderá se exibir publicamente, não poderá aceitar propostas outras, mais vantajosas. Pertence ao cassino que, durante três anos, terá na figura do negrinho uma ótima fonte de renda. Sim, porque é lógico que se Jóca não fosse fazer sucesso, Rolas não o trataria com tão paternal bondade. (...)Na estação Pedro II, Joca diz que vai para a Urca. Vai mesmo a pé, debaixo da chuva, porque não tem dinheiro para o transporte. 0 repórter adianta-lhe um níquel. E o negrinho, miúdo e inquieto, toma o bonde, feliz, muito feliz, a roupa branca salpicada da lama escura do subúrbio. Grita do bonde para o repórter: - Good bye!" (DIRETRIZES, 1941: ED 49, p. 20)

Dentro do universo cáustico, irônico e crítico de Joel Silveira há um artigo especialmente mordaz, na edição 178, Granfinos em São Paulo: dos lucros da guerra, nasce o esplendor da "haute gomme" paulista, no qual Silveira vai apresentar a classe dominante paulista depois de passar uma semana em São Paulo e circulado no grand monde, ter conhecido banqueiros, intelectuais, monarquistas e mulheres belíssimas. Haute gomme é o mundo elegante.

16 Segundo Patrícia Peixão, em seu blog no portal Comunique-se, esta seria uma das reportagens de maior repercussão. Riqueza e luxo parecem ser dois ingredientes que atraem leitores para alimentar sonhos e delírios vividos por alguns happy few. Visitar as casas luxuosas classe dominante, conhecer as famílias quatrocentonas, ser convidados a inúmeras festas foi uma ideia - segundo Patrícia - do amigo e pintor modernista Di Cavalcanti: "O artista tinha acabado de voltar de Paris e comentou com Joel que não estava sendo bem aceito pela grã-finagem paulistana, que era muito fechada, rejeitando o ingresso de pessoas que não pertenciam àquele mundo. Joel achou que aquilo rendia uma reportagem e começou suas incursões naquele universo, disfarçado como gentleman. Foi assim que nasceu o texto intitulado "1943: Eram assim os grã-finos em São Paulo", que descreve, com ironia e detalhes, toda futilidade 
de parte da elite paulistana daquele período. Por conta do estilo ácido e ferino, ganhou de Assis Chateaubriand, dono da maior rede de comunicação da época (os Diários Associados, responsável pela introdução da TV no Brasil), o apelido de "vibora", e foi convidado para trabalhar com ele". (PAIXÃO, 2017)

O texto é uma aula de escrita e pode ser comparada ao texto Frank Sinatra está resfriado, de Gay Talese, publicado na revista norte-americana Esquire, em 1965 (Fama e anonimato, Cia das Letras, 2004) quando o repórter faz um perfil de Sinatra sem entrevistar o cantor, apenas ouvindo amigos familiares, colegas de trabalho, pois o cantor não poderia falar com ele por estar resfriado. "Os rapazes se vestem muito bem e telefonam. Telefonam de cinco em cinco minutos e conversam com Lili, com Fifi, com Lelé. Recebem também telefonemas de Fifi, de Lili e de Lelé. (...)" (DIRETRIZES, 1943: ED 178, p. 1) relata Joel, em um dos trechos sarcásticos da matéria.

O que mais chama atenção no texto de Joel é grande quantidade de adjetivos que Silveira utiliza, além de uma proposital repetição - quase em cada parágrafo da longa matéria - da palavra granfino, no feminino, masculino, singular e plural. O texto tem uma apuração primorosa, ouvindo várias fontes entre os ricos e cuidando dos detalhes e dos contrastes presentes na São Paulo durante a Guerra. Faz várias comparações entre o dolce far niente da classe privilegiada e os operários que se organizam em mais de um turno para darem conta das máquinas de guerra que estão sendo fabricadas na capital paulista, movendo a economia. Joel abre a matéria contando que passou uma semana em São Paulo observando aquele nicho da sociedade no seu habitat: festas em casas deslumbrantes e o chá do Jequiti Bar: "Durante uma semana, fiquei atordoado com a vida elegante de São Paulo. Haviam-me levado para algumas festas: primeiro um aperitivo, colorido e com pedaços de fruta dentro, depois uma carreira rápida de automóvel. Estive em jantares faiscantes. As mulheres muito belas e perfumadas. Particularmente aquelas que puxam os cabelos para cima, num jeito que abandona aos nossos olhos as lindas nucas nuas. Durante uma tarde inteira, fiquei semi-deitado numa poltrona de um apartamento chique, no centro da cidade. (...) Fui de mistura com outros, como penetra. Os rapazes se vestem muito bem, e telefonam. Telefonam de cinco em cinco minutos e conversam com Lili, com Fifi, com Lélé. Recebem também telefonemas de Fifi, de Lili e de Lelé. (...) Um dos hábitos: conversar sobre os feitos da noite anterior na pista do Jequití.São Paulo sempre teve seu mundo de luxo, um mundo essencialmente gran fino. É coisa que acontece com todas as cidades que enriquecem. A riqueza paulista, é sabido, vem de suas fábricas. Agora as fábricas estão trabalhando da ainda mais, porque a guerra é exigente. Dia e noite, os motores não param. Há uma turma de operários que passa o dia inteiro diante dos motores. Quando a noite chega, a turma diurna vai embora, muito cansada, e chega outra que se cansará até de madrugada". (DIRETRIZES, 1943: ED 178, p. 1)

19 Adjetivos como atordoado, faiscante, belas e perfumadas, chique, repetições de telefone, telefonemas - também impensáveis em tetos informativos - aqui cabem para marcar o grau de empenho em se comunicar com pessoas do grand monde. Esse turbilhão de perfumes de salão e farfalhar de roupas caras em nenhum momento seduzem Joel que em meio à descrição dessa classe, constrói um texto sensível à brutal diferença desse grupo que pouco trabalhar e mais telefona com a classe operária qe está longe do paraíso. Monta um parágrafo usando o edifício Martinelli um dos ícones da arquitetura paulista como palco de um suicídio "um rapaz paulista, faminto e desempregado, resolveu se matar." Ao chegar no topo o jovem desiste do que seria o maior salto da América do Sul.

Pode se perceber que em quase todos os parágrafos ele elege um adjetivo que vai repetir ao longo daquele espaço, como milionário, por exemplo: "Mas os milionários são muitos. 
Raros são os milionários poetas em São Paulo, mas há muitos outros que não fazem versos. Uma noite, no Jequití Bar, conheci alguns deles: o milionário Lafer, o milionário Pignatari, o milionário Matarazzo, o milionário Crespi. Era uma festa somente para milionários, e sobre todos aqueles sobrenomes repousava a força paulista de hoje. (...) Com um gesto de mão, qualquer um deles poderia me aniquilar, me tanger longe, lá na rua. Mas os milionários apenas sorriam". (DIRETRIZES, 1943: ED 178, p. 1)

21 Lembra que há muitos endinheirados mas poucos poetas e que aqueles sobrenomes que desfilavam nas festas, rodopiam nas pistas ou se movem pelas casa de chá, na verdade são filhos de imigrantes pobres que chegaram ao Brasil com a esperança de melhorarem suas vidas e nenhum dinheiro no bolso, que trabalharam e agora a segunda geração aproveitava as delícias do luxo e da riqueza. Critica os jogos de carta tanto dos homens quanto das mulheres "fazendo coisas inúteis" e os homens vão ao Automóvel Clube, no final da tarde, lugar que descreve como "triste como um cemitério. Se no Rio, a praia congrega as diferentes turmas, aprende-se com Silveira que "O Jequiti é o mar noturno onde todos se encontram. Um mar de felicidade onde todas as possíveis tristezas e decepções se diluem e se inutilizam" (SILVEIRA, 1998).

E o chá na Jaraguá? É lá que as mulheres vão desfilar seus novos modelos e os cortes de cabelo Lili, Zezé e Lelé não perdem um chá na Jaraguá, que era uma livraria com um café nos fundos. $\mathrm{O}$ que era para ser um ponto de encontro de intelectuais, abriga a maior parte do high society paulista. Silveira ainda traça um raio $\mathrm{X}$ dos ricos dividindo-os em 3 categorias: os granfinos de pedigree, os paulistas quatrocentões, o grupo "reserva" que sonha em fazer parte do primeiro grupo. São as filhas dos italianos ricos e o terceiro grupo "lamentável e melancólico", os médicos de Barretos ou comerciantes de Bauru. Uma gente que não tem dinheiro. Os homens vivem de seus pequenos ganchos e comissões: "Os homens se dependuram na vida mundana de São Paulo como se estivessem num bonde cheio. As mulheres usam terríveis penachos, porque acreditam ser isto a característica principal da granfina, como o dente de ouro é característica de todo turco". (...) (DIRETRIZES, 1943: ED 178, p. 2)

E há os colunistas sociais Jerry e Bilm. Nenhuma festa acontece sem a presença deles que escrevem em jornais distintos, mas registram as presenças de todos os granfinos em suas colunas. Eles são mais importantes do que os Matarazzo ou Crespi. Eles garantem o sucesso ou fracasso dos granfinos. Poucos literatos fazem parte dessa tribo. Oswaldo de Andrade chegou a entrar para o seleto grupo, mas caiu em desgraça ao perder sua fortuna. Alfineta Di Cavalcanti que costuma ir às festas e vender alguns de seus quadros. "Não é um diletante".

Ao entrevistar uma das Fifis, ela lhe confessa que a vida social em São Paulo nunca foi tão intensa. Ao que Silveira termina seu texto lembrando que enquanto uns gastam outros se matam de trabalhar, correndo em ônibus e trens apertados. "O Brasil está vivendo uma era de fartura. Uma fartura que, na verdade, não chega para todos. Mas chega para Fifi, para Lélé e para Mimi, orquídeas raras. De noite, quando se acendem as luzes de São Paulo, a cidade fica ainda mais imponente. Os anúncios luminosos rasgam o céu: são anúncios das melhores e mais poderosas coisas da América do Sul. Há centenas de indústrias em São Paulo. Cada indústria tem um anúncio luminoso, um anuncio alegre. Cada indústria pede centenas de motores, cada motor pede dezenas de operários. Dia e noite os operários manejam os motores. Os motores fazem dinheiro. Os olhos e o sorriso de Jerry se derramam satisfeitos sobre Fifi, como se Fifi fosse criação da sua coluna mundana na 'Folha da Manhã'”. (...) (DIRETRIZES, 1943: ED 178, p. 26) 


\section{Tabela}

Tabela 1: Relação de matérias publicadas por Joel Silveira em Diretrizes. Na primeira coluna, consta a edição de Diretrizes na qual o texto foi publicado; na segunda, o título original da reportagem; por fim, na terceira, uma breve síntese do assunto abordado.

\begin{tabular}{|c|c|c|}
\hline ED & TÍTULO DA MATÉRIA & SÍNTESE \\
\hline 49 & Escravos de Contrato & $\begin{array}{l}\text { Reportagem sobre o jovem ator negro Jayme Pedro da Silva, } \\
\text { apelidado Joca, de origens humildes e que está preso por um } \\
\text { contrato ao Cassino após fazer sucesso na adaptação para o } \\
\text { cinema de 'Pureza'. o filme foi muito criticado, mas o trabalho } \\
\text { do ator foi exaltado pela crítica. }\end{array}$ \\
\hline 53 & Vendedores de Humor & $\begin{array}{l}\text { Entrevistas com humoristas como Terra de Sena, Yantok } \\
\text { Cesarino e Raul Perdeneiras sobre as condições de trabalho e } \\
\text { questões como a popularidade dos trocadilhos. }\end{array}$ \\
\hline 68 & $\begin{array}{l}\text { As aventuras de um médico } \\
\text { da missão Rondon }\end{array}$ & $\begin{array}{l}\text { Reportagem sobre Esperidião de Carvalho, médico que fez } \\
\text { uma intervenção cirurgia em Roosevelt. }\end{array}$ \\
\hline 80 & $\begin{array}{l}\text { A mais bela história de amor } \\
\text { do Brasil }\end{array}$ & $\begin{array}{l}\text { Entrevista com Narazeth Prado, viúva do modernista Graça } \\
\text { Aranha. A entrevista está repleta de relatos de Prado sobre } \\
\text { experiências intimas do casal e a viúva chega a dizer que o } \\
\text { marido jamais foi um Modernista, que a Semana de Arte } \\
\text { Moderna só foi um pretexto para visita-la em São Paulo. }\end{array}$ \\
\hline 100 & $\begin{array}{l}0 \quad \text { integralismo vive } \\
\text { atualmente uma existência } \\
\text { de conspiração subterrânea }\end{array}$ & $\begin{array}{l}\text { Entrevista com João Neves da Fontoura, que revela alguns } \\
\text { detalhes dos bastidores da chamada "Revolução de } 30 \text { " e se } \\
\text { defende das acusações realizadas por Plínio Salgado, anos } \\
\text { antes, que havia lhe chamado de integralista. }\end{array}$ \\
\hline 116 & $\begin{array}{l}\text { Os estudantes do Brasil } \\
\text { mobilizados contra o nazismo } \\
\text { internacional }\end{array}$ & $\begin{array}{l}\text { Reportagem sobre a postura dos estudantes brasileiros que, } \\
\text { por intermédio da UNE, tomaram a frente de diversas } \\
\text { manifestações pelo país contra os regimes fascistas e } \\
\text { publicaram alguns manifestos. }\end{array}$ \\
\hline 117 & $\begin{array}{l}\text { "O trabalhador brasileiro } \\
\text { repudia completamente o } \\
\text { nazi-nipo-fascismo" }\end{array}$ & $\begin{array}{l}\text { Entrevista com Góis Monteiro à época Presidente do Conselho } \\
\text { Nacional do Trabalho. o coronel emite opiniões } \\
\text { extremamente radicas a respeito dos imigrantes oriundos de } \\
\text { países do Eixo, defendendo que o governo deveria tratar a } \\
\text { todos como inimigos. }\end{array}$ \\
\hline 122 & $\begin{array}{l}\text { Dez homens contra uma } \\
\text { classe }\end{array}$ & $\begin{array}{l}\text { Reportagem sobre a greve dos motoristas de bondes, que se } \\
\text { organizaram a fim de alcançar melhores condições de } \\
\text { trabalho com o aumento da demanda pelos transportes } \\
\text { devido à crise dos combustíveis. }\end{array}$ \\
\hline
\end{tabular}




\begin{tabular}{|c|c|c|}
\hline 167 & $\begin{array}{l}\text { "O trabalhador brasileiro } \\
\text { repudia completamente o } \\
\text { nazi-nipo-fascismo" }\end{array}$ & $\begin{array}{l}\text { Entrevista com Góis Monteiro à época Presidente do Conselho } \\
\text { Nacional do Trabalho. o coronel emite opiniôes } \\
\text { extremamente radicas a respeito dos imigrantes oriundos de } \\
\text { países do Eixo, defendendo que o governo deveria tratar a } \\
\text { todos como inimigos. }\end{array}$ \\
\hline 163 & $\begin{array}{l}\text { "Sou contra os sindicatos } \\
\text { literários": Genolino Amado } \\
\text { denuncia a ação das } \\
\text { "igrejinhas" intelectuais }\end{array}$ & $\begin{array}{l}\text { Entrevista com Genolino Amado, que explica sua ausência nas } \\
\text { páginas dos jornais durante a guerra. Ele diz que o momento } \\
\text { não era propício para o tipo de texto que costumava publicar, } \\
\text { uma vez que o horror da guerra dominava as manchetes. }\end{array}$ \\
\hline 178 & $\begin{array}{l}\text { Granfinos em São Paulo: dos } \\
\text { lucros da guerra, nasce o } \\
\text { esplendor da "haute gomme" } \\
\text { paulista }\end{array}$ & $\begin{array}{l}\text { Reportagem mais importante publicada por Joel Silveira em } \\
\text { Diretrizes, rendendo-lhe a admiração de Assis Chateaubriand } \\
\text { e o apelido de "víbora". No texto, Silveira relata o cotidiano da } \\
\text { elite paulista debochando da futilidade das pessoas. }\end{array}$ \\
\hline 203 & A miséria cria um mundo & $\begin{array}{l}\text { Reportagem sobre as condições desumanas vivenciadas por } \\
\text { famílias no Rio Grande do Sul }\end{array}$ \\
\hline 207 & $\begin{array}{l}\text { Os rios da miséria correm } \\
\text { para aquele mar }\end{array}$ & $\begin{array}{l}\text { Reportagem sobre o possível fechamento da Fundação Gafrée } \\
\text { e Guinle, no Rio de Janeiro, local de atendimentos médicos } \\
\text { para pessoas de baixa renda e que prestava grande } \\
\text { contribuição no controle de doenças como a sífilis. }\end{array}$ \\
\hline
\end{tabular}

\section{BIBLIOGRAFIA}

DIRETRIZES: Política, Economia e Cultura. Rio de Janeiro, 1938-1944. Disponível em: <http:// bndigital.bn.br/acervo-digital/diretrizes/163880>. Acesso em: 10. abr. 2018.

DUQUE FILHO, A. X.. Política Internacional na revista Diretrizes (1938-1944). Disponível em:< http:// repositorio.unesp.br/bitstream/handle/11449/93438/duquefilho_ax_me_assis.pdf>. Acesso em: 10. abr. 2018.

FERRARI, Danilo Wenseslau. A atuação de Joel Silveira na imprensa carioca (1937-1944). Cultura Acadêmica, São Paulo, 2012.

OLIVEIRA, C. F. P. A Política Externa do governo Vargas durante o Estado Novo e a construção da Companhia Siderúrgica Nacional. Disponível em: < https://ojs.franca.unesp.br/index.php/ historiaecultura/article/view/1480>. Acesso em: 10. abr. 2018.

PAIXÃO, Patrícia. Dez anos sem Joel Silveira: textos e lições de um dos grande repórter. Disponivel em: < https://portal.comunique-se.com.br/joel-silveira-textos-licoes-maiores-reporteres/>. Acesso em 10 ago. 2018.

PESAVENTO, Sandra. Cidades. Disponível em: <http://www.scielo.br/scielo.php? script=sci_arttext\&pid=S0102-01882007000100002>. Acesso em 10. jul. 2018. 
ROUCHOU, Joëlle; RESENDE, Yuri. Diretrizes e as crônicas de Rubem Braga (1938-1939). Disponível em: < http://www.historiadamidiasudeste.com/uploads/8/0/3/0/80305748/mi02.pdf>. Acesso em 10. abr. 2018.

SILVEIRA, Joel. Na fogueira, memórias Mauad, Rio de Janeiro, 1998.

WAINER, Samuel Minha razão de viver. Record, Rio de Janeiro, 1987.

WERNECK SODRÉ, Nelson. História da Imprensa. Mauad, Rio de Janeiro, 1999.

\section{RESUMOS}

Dando continuidade à pesquisa sobre a revista Diretrizes (1938-1944), nos interessa analisar o trabalho do jornalista Joel Silveira que foi secretário de redação e repórter na publicação dirigida por Samuel Wainer. Vamos inicialmente trabalhar com as matérias de capa de Silveira durante o período da II Guerra Mundial e buscar compreender as relações entre o cotidiano nacional, o clima de guerra e a função do jornalista em momento de exceção, como é um estado de guerra. Não se pode deixar de trabalhar com a questão da censura do DIP (Departamento de Imprensa e Propaganda - do governo de Getúlio Vargas). Nos interessa olhar para as relações entre os jornalistas e a disputa velada em qual matéria irá para a capa da revista, as sensibilidades latentes no ambiente da redação.

Nous analyserons le travail du journaliste Joel Silveira dans le magazine Diretrizes (1938-1944), secrétaire de rédaction et reporter dans l'hebdomadaire dirigé par le journaliste Samuel Wainer. Dans un premier moment nous travaillerons sur les reportages publiés à la une de la revue pendant la Deuxième Guerre mondiale, en essayant de comprendre le quotidien national, l'ambiance de la guerre et la fonction du journalisme et du journaliste dans ces moments d'exception que sont les temps de guerre. Nous allons étudier aussi les démarches de la rédaction contre la censure venue du DIP (Département de Presse et de propagande - du gouvernement de Getúlio Vargas). La lutte des journalistes pour être publiés en première page sera aussi visitée ainsi que le climat sensible qui règne dans les rédactions.

\section{ÍNDICE}

Mots-clés: journalisme - repórter - presse - Joel Silveira - Diretrizes

Palavras-chave: jornalismo - repórter - imprensa -Joel Silveira - Diretrizes

\section{AUTOR}

\section{JOËLLE ROUCHOU}

Doutora pela ECA/USP e pesquisadora na Fundação Casa de Rui Barbosa, com foco em história da imprensa.

joelle@rb.gov.br 